Dhaka Univ. J. Biol. Sci. 28(2): 219-226, 2019 (July)

\title{
ANTAGONISTIC POTENTIAL OF SOIL FUNGI AGAINST COLLETOTRICHUM GLOEOSPORIODES (PENZ .) SACC., THE CAUSAL AGENT OF ANTHRACNOSE OF RAUWOLFIA SERPENTINA (L.) BENTH. EX KURZ
}

\author{
ZuHRA YASMIN ${ }^{1}$ AND SHAMIM SHAMSI* \\ Department of Botany, University of Dhaka, Dhaka-1000, Bangladesh
}

Key words: Antagonistic potentiality, Soil fungi, Colletotrichum gloeosporiodes, Anthracnose, Rauwolfia serpentina

\begin{abstract}
Four antagonistic fungi Aspergillus flavus Link, A. fumigatus Fresenius, A. niger van Tiegh. and Trichoderma viride Pers. were isolated from field soil of Rauwolfia serpentina by serial dilution method and selected to evaluate their antagonistic potentiality against Colletotrichum gloeosporiodes (Penz.) Sacc, the causal agent of anthracnose of Rauwolfia serpentina (L.) Benth. ex Kurz following dual culture colony interaction, volatile and non-volatile metabolites. In dual culture method Trichoderma viride showed maximum (84.28\%) inhibition of test fungi followed by Aspergillus niger (77.39\%), A. fumigatus (43.71\%) and A. flavus $(29.32 \%)$. Volatile metabolites of T. viride showed higher (77.64\%) inhibition of test fungi followed by A. flavus (75.58\%), A. fumigatus (60.88\%) and A. niger $(58.23 \%)$. Non-volatile metabolites of antagonistic fungi showed that A. flavus showed $(94.42 \%)$ inhibition of test fungus followed by T. viride $(90.90 \%)$, A. niger (86.13\%) and A. fumigatus (73.73\%). Aspergillus flavus, A. niger and T. viride may be exploited commercially as a biocontrol agent against anthracnose disease of $R$. serpentina.
\end{abstract}

\section{Introduction}

Rauwolfia serpentina (L.) Benth. ex Kurz is a medicinal shrub belongs to the family Apocynaceae. The shrub is locally known as "Sarpagandha" and also known as Indian snakeroot. It grows in India, Thailand and other parts of Asia, South America and Africa. It is widely distributed in the sub-Himalayan tract from Punjab to Nepal, Sikkim and Bhutan ${ }^{(1)}$. In Bangladesh it grows in Chittagong, Dhaka, Sylhet and Mymensingh(2). International Union for Conservation of Nature (IUCN) has placed this plant under endangered status ${ }^{(3)}$. Root of this shrub is mostly used as a good antidote for high blood pressure. Seventeen different alkaloids have been extracted from the bark of the root of this shrub(4). Serpertine is one of those alkaloids.

*Author for correspondence: <prof.shamsi@gmail.com>. ${ }^{1} \mathrm{~A}$ part of Ph.D. thesis of first author. 
Diseases are a major source of leaf and plant damage that can be caused by a number of plant pathogenic organisms. Fungal diseases are the number one cause of plant loss worldwide. A fungicide is a specific type of pesticide that controls fungal disease by specifically inhibiting or killing the fungus causing the disease. Fungi often spoil stored fruits, vegetables, tubers, and seeds. A few infect grains to produce toxins (mycotoxins) capable of causing severe illness or even death in humans and animals when consumed. Fungicides are biocidal chemical compounds or biological organisms used to kill or inhibit fungi or fungal spores. Fungi can cause serious damage in agriculture, resulting in critical losses of yield, quality, and profit. Fungicides are used both in agriculture and to fight fungal infections in animals.

Over the past few decades, farmers have increasingly relied on chemical pesticides for protecting plants against pathogens. Biological control of plant diseases including fungal pathogens has been considered a viable alternative method to chemical control. Biological control presents a better alternative with relative low cost, no side effects and reduced resistance development in the pathogen (5-6).

Study of antagonist as biological control agent has now become one of the most exciting and rapidly developing areas in plant pathology because it has great potential to solve many agricultural and environmental problems. At present, Trichoderma-based products are considered as relatively novel biological control agents which can help farmers to reduce plant diseases and increase plant growth ${ }^{(7)}$.

In Bangladesh, research on biological control of fungal diseases of $R$. serpentina is very limited. So, for the sake of economy we need more information in this regard. Considering the importance of this endangered plant, present investigation was undertaken to find out the efficacy of antagonistic fungi against $C$. gloeosporiodes the causal agent of anthracnose of $R$. serpentina.

\section{Materials and Methods}

An investigation was carried out to find out the fungi associated with leaves of $R$. serpentina during April, 2007 to August, 2013. Infected leaves of R. serpentina having characteristic samples were collected from four different locations namely, Curzon Hall Campus, Dhaka University, Lawachara Sylhet, Botanic Garden, Chittagong University Campus and Mymensingh Agricultural University campus properly and then brought to the laboratory of Mycology and Plant Pathology, Department of Botany, University of Dhaka. The fungi associated with infected leaves were isolated following "Tissue planting method" on PDA medium(8). A total of 15 species of fungi were isolated from infected leaves of $R$. serpentina. Pathogenecity test of the isolated fungi were done following 'Detached leaf technique' and 'Spraying of spore suspension' on healthy plants. Among the isolated fungi C. gloeosporiodes was found to be pathogenic to $R$. serpentina(9). 
Serial dilution method was used to isolate antagonistic fungi from rhizosphere soil of the host plant. Among the isolated soil fungi, Aspergillus flavus, A. fumigatus, A. niger and T. viride were selected to test their antagonistic potential against the following dual culture technique ${ }^{(10)}$. The parameter used for the assessment of the colony interaction and per cent inhibition of radial growth was calculated ${ }^{(11)}$. Effects of volatile and non-volatile metabolites of the selected soil fungi against the test pathogens were also studied. Data on different parameters were analyzed following computer package MSTAT-C and means were compared using DMRT. The data were collected and evaluated by analysis of variance (ANOVA) by using STAR statistical program.

\section{Results and Discussion}

Fifteen species of fungi, namely Alternaria alternata (Fr.) Keissler, Aspergillus flavus Link ex Fr. Aspergillus niger van Tieghme, Colletotrichum gloeosporioides (Penz.) Sacc., Curvularia lunata (Wakker) Boedijn, Fusarium sp. 1, Fusarium sp. 2, Macrophoma sp., Nigrospora sphaerica (Sacc.) Mason, Penicillium digitatum Saccardo, Penicillium italicum Whemer, Pestalotiopsis guepinii (Desm.) Stay, Pseudocercospora liebenbergii ( Syd.) Deighton, Rhizopus stolonifer Bull. Toney, Trichoderma viride Pers were found to be associated with diseased $R$. serpentina. Among the isolated fungi one was found to be pathogenic to $R$. serpentina. The pathogenic fungus was $C$. gloeosporioides. The pathogenic fungus was selected as test pathogen against selected four antagonistic fungi.

The results of colony interactions are summarized in Table 1 and Fig. 1. In this study, antagonistic relationships (Grade) among the soil fungi and test pathogens were 2 and 4 . However, grade 2 was found to be the most commonly encountered type of colony interaction as 10 interactions were incorporated in this grade which was followed by grade 4 ( 2 out of 12 ) (Table 1 ).

Table 1. Colony interaction between Colletotrichum gloeosporioides and antagonists.

\begin{tabular}{|c|c|c|c|c|c|}
\hline $\begin{array}{l}\text { Name of } \\
\text { antagonists }\end{array}$ & Grade* & Type** & $\begin{array}{l}\% \text { inhibition of colony } \\
\text { of the pathogens }\end{array}$ & $\begin{array}{l}\text { Intermingled } \\
\text { zone }(\mathrm{cm})\end{array}$ & $\begin{array}{l}\text { Inhibition } \\
\text { zone }(\mathrm{cm})\end{array}$ \\
\hline Aspergillus flavus & 2 & Bii & 40.26 & - & - \\
\hline A. fumigatus & 2 & Bii & 36.84 & 0.2 & - \\
\hline A. niger & 4 & $\mathrm{C}$ & 43.48 & - & 0.2 \\
\hline Trichoderma viride & 2 & Bii & 66.67 & 0.2 & - \\
\hline
\end{tabular}

- = Absent, ${ }^{*}=$ Grades from 1 (mutually intermingling growth) to 5 (mutual inhibition at a distance), based on Skidmore and Dickinson (1976). ${ }^{*}$ Bii = Intermingling growth where the fungus under observation has ceased the growth and is being overgrown by another colony (2). C = Slight inhibition with a narrow demarcation line, 1 - $2 \mathrm{~mm}$ (4). 


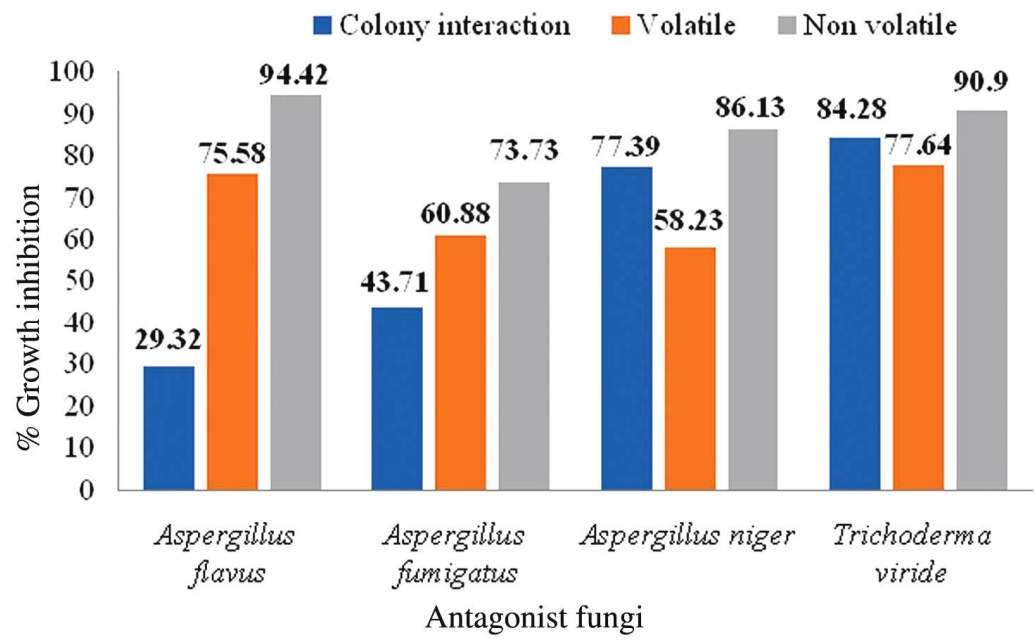

Fig 1. Evaluation of in vitro inhibition of Colletotrichum gloeosporoides using antagonistic fungi in different methods.

Figs 1 and 2 show that in dual culture colony interaction T. viride showed the highest growth inhibition on C. gloeosporioides (84.28\%) which was followed by Aspergillus niger (77.39\%), A.flavus (43.71\%) and A. fumigatus (29.32\%).
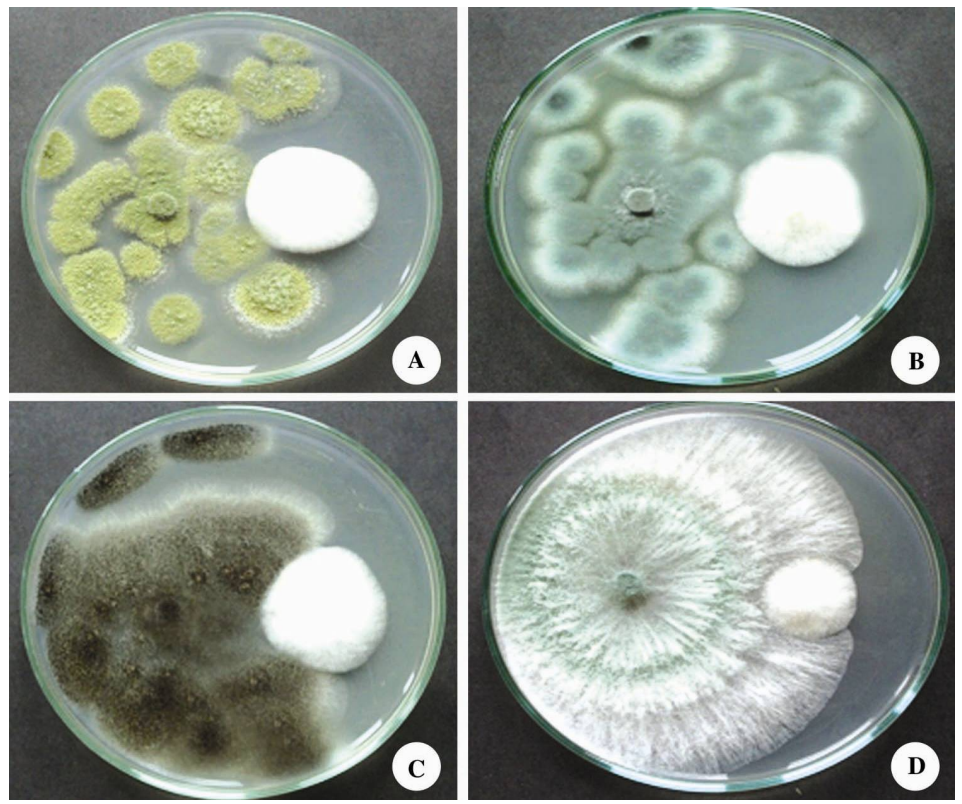

Fig. 2. Colony interaction between Colletotrichum gloeosporioides and antagonists. A. Colletotrichum gloeosporioides and Aspergillus flavus. B. C. gloeosporioides and A. fumigatus. C. C. gloeosporioides and A. niger. D. C. gloeosporioides and Trichoderma viride. 
In contrast to the present study, Akter et al.(12) reported that in dual culture colony interaction A. niger, T. viride, A. flavus and A. fumigatus showed 68.66, 57.24, 54.19 and $50.25 \%$ growth inhibition on Colletotrichum sp., respectively. Again Aspergillus niger, Trichoderma viride, A. flavus and A. fumigaus showed 75.87, 75.5, 51.78 and $45.52 \%$ growth inhibition on Curvularia lunata, respectively. Further T. viride, A. niger, A. flavus and A. fumigatus showed 56.52, 50.70, 47.36 and $46.15 \%$ growth inhibition on Fusarium semitectum, respectively. Bashar and Chakma ${ }^{(13)}$ reported that in dual culture colony interaction A. niger, T. viride, A. flavus and A. fumigatus showed 65.21, 64.24, 57.14 and $34.78 \%$ growth inhibition on $F$. oxysporum, respectively. This variation might be due to selection of different test pathogens. In dual culture technique, significantly maximum inhibition was recorded in T. viride $(66.40 \%)$ according to Patel and Joshi ${ }^{(14)}$.

Tapwal et al.(15) reported that in dual culture colony interaction $T$. viride showed $12.50 \%$ growth inhibition on C. gloeosporioides. The same antagonist also showed different effects on different fungi in the present investigation. This variation might be due to selection of different test pathogens. In dual culture technique, significantly maximum inhibition was recorded in T. viride (66.40\%) according to Patel and Joshi ${ }^{(14)}$.

The results on the effect of volatile metabolites of antagonistic fungi against R. serpentina pathogens are presented in Figs 1 and 3. The maximum inhibition of radial growth of $C$. gloeosporioides was observed in T. viride (77.64\%) which was followed by $A$. flavus $(75.58 \%)$, A. fumigatus (60.88\%) and A. niger (58.23\%) due to the volatile metabolites after 6 days of incubation at $25 \pm 2^{\circ} \mathrm{C}$.
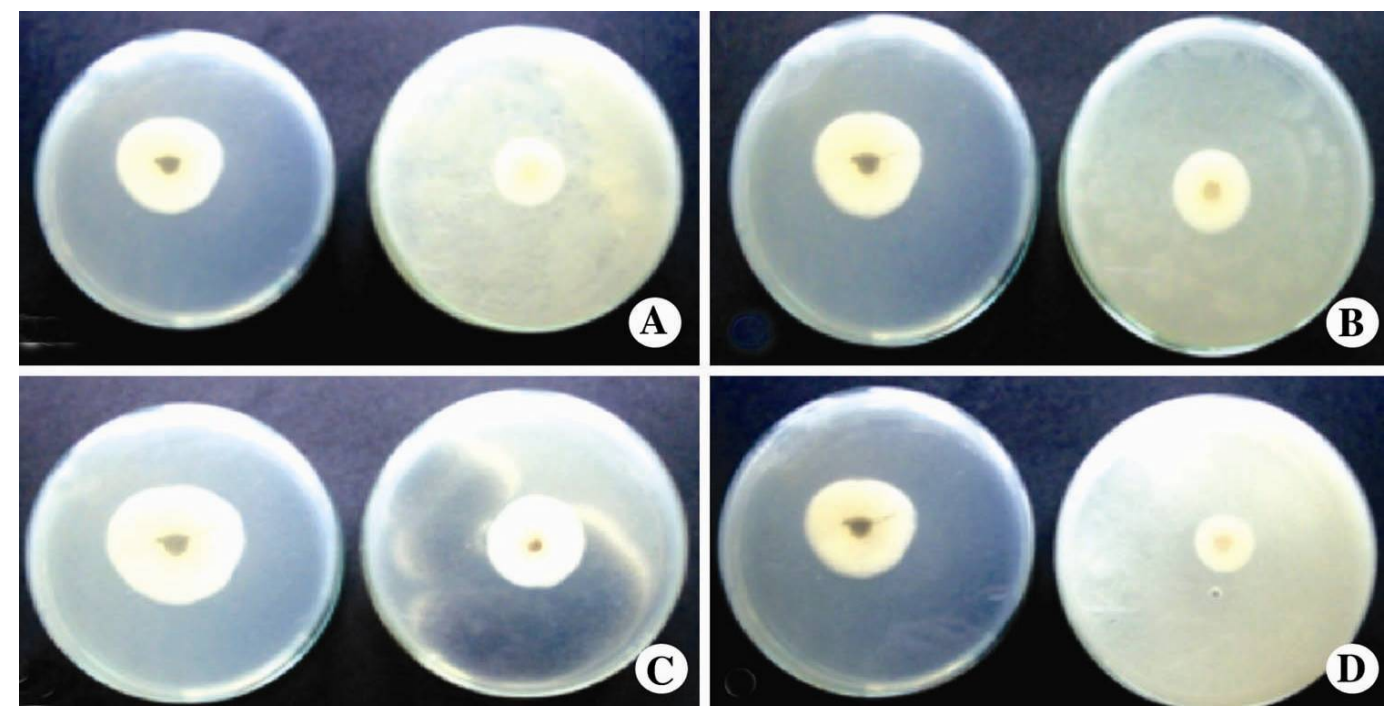

Fig. 3. Growth inhibition of Colletotrichum gloeosporioides owing to volatile metabolites of antagonists. A. Colletotrichum gloeosporioides: Aspergillus flavus. B. C. gloeosporioides: A. fumigatus. C. C. gloeosporioides: A. niger and D. C. gloeosporioides: Trichoderma viride. 
In contrast to the result of present study, Aktar et al.(12) reported that volatile metabolites produced by isolates of $A$. niger, A. flavus, A. fumigatus and T. viride inhibited the mycelial growth of Colletotrichum sp. by 14.68, 11.78, 11 and $11 \%$, respectively. In addition the volatile metabolites produced by isolates of $T$. viride, A. niger, A. flavus and A. fumigatus inhibited the mycelial growth of F. semitectum by 13.5, 9.5, 8 and 7.75\%, respectively. Differences in per cent inhibition with the present study might be due to the difference in organism involved in the interaction. Bashar and Chakma ${ }^{(13)}$ reported that volatile substances produced by T. viride, A. niger, A. flavus and A. fumigatus showed $29.75,20.15,15.78$ and $12.25 \%$ growth inhibition on F. oxysporum, respectively. Thakur and Harsh ${ }^{(16)}$ reported that volatile metabolites produced from the culture of A. niger showed $42.43 \%$ inhibition of mycelial growth of C. gloeosporioides.

Figs 1 and 4 show the effect of non-volatile metabolites on the growth of Colletotrichum aswas observed with the culture filtrates of A. flavus $(94.42 \%)$, which was followed by T. viride (90.90\%). A. niger $(86.13 \%)$ and A. fumigatus $(73.73 \%)$ at $20 \%$ concentration.
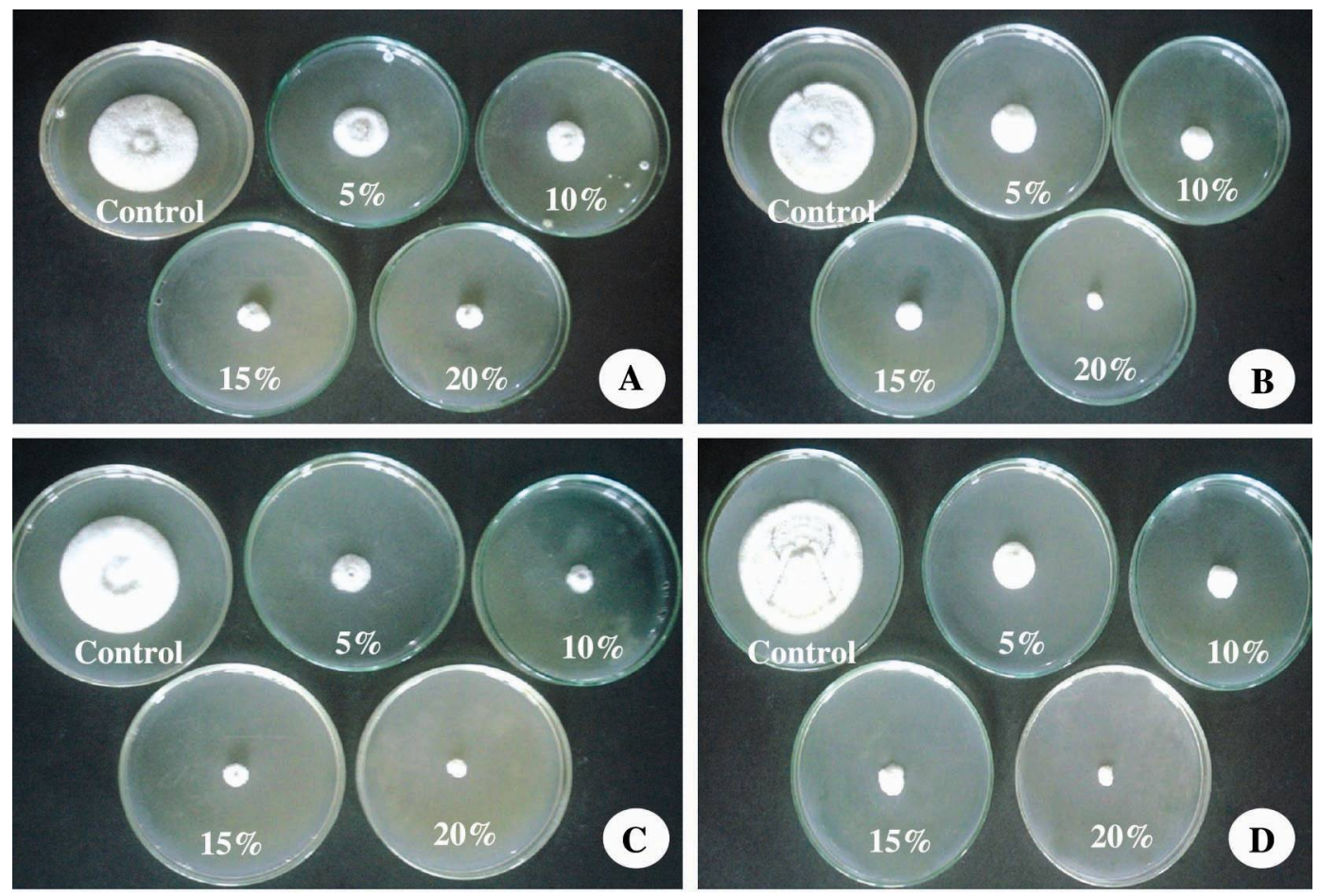

Fig. 4. Growth inhibition of Colletotrichum gloeosporioides owing to non-volatile metabolites of four antagonists at 5, 10, 15 and 20\% concentrations. A. Colletotrichum gloeosporioides: Aspergillus flavus. B. C. gloeosporioides: A. fumigatus. C. C. gloeosporioides: A. niger. D. Cgloeosporioides : Trichoderma viride. 
In contrast to the data obtained in the present study, Aktar et al.(12) reported that nonvolatile metabolites produced by isolates of A.niger, T. viride, A. flavus and A. fumigatus inhibited mycelial growth of Colletotrichum sp. by 52.56, 44.72, 40 and $37.2 \%$, respectively. Further, the non-volatile metabolites produced by an isolate of T. viride, A. niger, A. flavus and A. fumigatus inhibited mycelial growth of $F$. semitectum by $50,45,8$ and $7.75 \%$, respectively. Differences in per cent inhibition with the present study might be due to the difference in organism strains involved in the interaction. Bashar and Chakma ${ }^{(13)}$ reported that culture filtrates of $T$. viride, A. fumigatus, A. niger and A. flavus showed $82.05,80.56,72.22$ and $66.66 \%$ growth inhibition of F. oxysporum at $20 \%$ concentration owing to non-volatile metabolites. Madhanraj et al.(17) reported that culture filtrates of $T$. viride and $A$. niger inhibited the mycelial growth of $F$. solani by 85 and $70 \%$ at 20 per cent concentration, respectively. Tran ${ }^{(7)}$ used T. virideto control S. rolfsii and found effective result. Tapwal et al. ${ }^{15)}$ reported that culture filtrates of $T$. viride showed $13.33 \%$ growth inhibition on C. gloeosporioides.

Two biocontrol agents viz., Aspergillus niger and Trichoderma viride were tested against ten white rot and one brown rot wood decay fungi (WDF) by dual culture technique under laboratory conditions. The result showed that both $A$. niger and $T$. viride inhibit growth of all WDF tested. The percentage inhibition of radial growth values of $T$. viride and $A$. niger are almost the same (ranging from 29.2 to 66.7) and the average mean value of T. viride (51.7) is 13.3 more than that of $A$. niger (45.5).(18)

The present investigation suggests that Aspergillus niger, A. fumigatus and Trichoderma viride may be exploited commercially as a biocontrol agent to protect anthracnose disease of $R$. serpentina caused by C. gloeosporioides.

\section{Acknowledgement}

The first author (ZY) wishes to expresses her gratitude to the Ministry of Science and Technology, the People's Republic of Bangladesh for providing financial assistance to this research work through NSICT fellowship program.

\section{References}

1. Ahmed ZU, Begum ZNT, Hassan MA and Khondker M, Kabir SMH, Ahmad M, Ahamad ATA, Rahman AKA and Haque EU (eds.). 2008. Encyclopedia of Flora and Fauna of Bangladesh, Vol.7. Angiosperms: Dicotyledones (Balsaminaceae-Euphorbiaceae). Asiatic society of Bangladesh,, Dhaka. pp. 546.

2. Chowdhury MSU. 1995. Country Report to the FAO International Technical Conference on Plant Genetic Resources, Bangladesh.

3. Mabberley, DJ 2008 Mabbeevly's plant- Book, A portable dictionary of plants their clarification and Vses, $3^{\text {rd }}$ ed. Cambridge University press, Cambridxviii+102. 
4. Panda H. 2004. Medicinal Plants Cultivation and their uses. Delhi, Asia Pacific Business Press. pp. 550.

5. Okigbo RN and Ikediugwu FEO 2000. Studies on biological control of post-harvest rot of yams (Dioscorea spp.) with Trichoderma viride. J .Phytropathol.148: 351.

6. Okigbo RN and Nmeka IA 2005. Control of yam tuber rot with leaf extracts of Xylopia aethiopics and Zingiber officinals. Afri. J. Biotechnol. 4(8): 804-807.

7. Tran N Ha 2010. Using Trichoderma species for biological control of plant pathogens in Viet Nam. J. ISSAAS. 16(1): 17-21.

8. Yasmin Z and Shamsi S 2015. Report on anthracnose of Rauwolfia serpentina (L.) Benth. ex Kurz caused by Colletotrichum gloeosporioides (Penz.) Sacc. from Bangladesh. J. Asiat. Soc. Bangladesh, Sci. 41(2): 183-192.

9. Yasmin Z and Shamsi S 2019. Incidence and severity of leaf spot and anthracnose diseases of Rauwolfia serpentine (L.) Benth. ex Kurz Bioresearch Communications 5(1): 670-677.

10. Bashar MA and Rai B 1994. Antagonistic potential of root-region microflora of chickpea against Fusarium oxysporum f. sp. ciceri. Bangladesh J. Bot. 23(1): 13-19.

11. Fokkema NJ 1976. Antagonism between fungal saprophytes and pathogens on aerial plant surfaces. In: Microbiology of Aerial Plant Surfaces (eds Dickinson CH and Preece TF), Academic Press, London. pp. 487-505.

12. Aktar MT, Hossain KS and Bashar MA 2014. Antagonistic potential of rhizosphere fungi against leaf spot and fruit rot pathogens of brinjal. Bangladesh J. Bot. 43(2) 213-217.

13. Bashar MA and Chakma M 2014. In vitro control of Fusarium solani and F. oxysporum the causative agent of brinjal wilt. Dhaka Univ. J. Biol. Sci. 23(1): 53-60.

14. Patel KD and Joshi KR 2001. Antogonistic effect of some bioagents in vitro against Colletotrichum gloeosporioides Penz. and Sacc. the causal agent of leaf spot of turmeric. J. Mycol. and Pl. Path. 31: 126.

15. Thapwal A, Tyagi A, Thakur G and Chandra S 2015. In vitro evaluation of Trichoderma species against seed borne pathogens. IJCBS research paper 1(10).

16. Thakur S and Harsh NSK 2014. In vitro potential of volatile metabolites of phylloplane fungi of Piper longumus biocontrol against plant pathogens. IJSN 5(1): 33-36.

17. Madhanraj P, Ambikapathy V and Panneerselvam A 2010. Biological control of banana wilt caused by Fusarium solani (Mart.) Sacc. International Journal of Applied Biology and Pharmaceutical Technology 1(3): 1032-1039.

18. Tiwari CK, Parihar J and Verma RK 2011. Potential of Aspergillus niger and Trichoderma viride as biocontrol agents of wood decay fungi. Journal of the Indian Academy of Wood Science 8(2): 169-172.

19. Skidmore AM and Dickinson CH 1976. Colony interaction and hyphal interference between Septoria nodorum and phylloplane fungi. Trans. Brit. Mycol. Soc. 66: 57-64. 